\title{
Origem e distribuição do nervo isquiático no veado-catingueiro (Mazama gouazoubira) ${ }^{1}$
}

\author{
Tracy Martina M. Martins², Kleber F. Pereira², Fabiano Campos Lima², André \\ L.Q. Santos ${ }^{3}$ e Taís Malysz ${ }^{2 *}$
}

\begin{abstract}
Martins T.M.M., Pereira K.F., Lima F.C., Santos A.L.Q. \& Malysz T. 2013. [Origin and distribution of the sciatic nerve in catingueiro-deer (Mazama gouazoubira).] Origem e distribuição do nervo isquiático no veado-catingueiro (Mazama gouazoubira). Pesquisa Veterinária Brasileira 33(2):273-278. Laboratório de Anatomia Humana e Comparativa, Curso de Ciências Biológicas, Universidade Federal de Goiás, Campus Jataí, BR364 Km192, Setor Parque Industrial, Jataí, GO 75800-000, Brazil. E-mail: taismalysz@yahoo.com.br

This study aimed to describe the origin and distribution of the sciatic nerve in catingueiro-deer (Mazama gouazoubira). Two animals of the species, obtained post mortem by trampling on the highway, were used for the study meeting the requirements of the Governing Law (1.153/95). By dissection the skin was completely removed and the animals were fixed in aqueous $10 \%$ formaldehyde solution. Through dorsolateral access, superficial gluteal muscle, biceps femoris muscle and gluteus medius muscle were cut at their insertion and folded, to view the origin and distribution of the sciatic nerve on both sides of the animals. Images were recorded with a digital camera (Sony a200 Camera, 10.2mpx) and results were described based on Veterinary Anatomical Nomina. The source data of the sciatic nerve in both specimens showed that the nerve originates from the ventral branches of S1 and L6, and could have contribution from S2. After its emergence through the greater sciatic foramen on both the sides, the sciatic nerve supplies branches to gluteus medius muscle, gluteus deep muscle, superficial gluteal muscle, gluteobiceps muscle, biceps femoris muscle, semimembranosus muscle, semitendinosus muscle and gastrocnemius muscle. Near the mid-thigh the sciatic nerve divides into the tibial nerve and common peroneal nerve which innervate the muscles of the distal hind limb. Moreover, the cutaneous nerve flow can cause the common peroneal nerve or tibial nerve. In conclusion, in Mazama gouazoubira specimens studied, the sciatic nerve originated from the ventral branch of spinal L6 and S1, which may or may not have the contribution from S2. In its distribution stem originate the gluteal nerve, the caudal femoral cutaneous nerve and muscular branches, which together innervate the muscles gluteus medius, gluteus deep, superficial gluteal, gluteobiceps, biceps femoris, semitendinosus, semimembranosus, adductor and gastrocnemius. Distally the sciatic nerve bifurcates into the common peroneal and tibial nerve, which innervates the distal hind limb.
\end{abstract}

INDEX TERMS: Sciatic nerve, morphology, Mazama gouazoubira.

RESUMO.- Este estudo teve como objetivo descrever a origem e a distribuição do nervo isquiático no veado-catingueiro (Mazama gouazoubira). Dois animais da espécie, obtidos

\footnotetext{
${ }^{1}$ Recebido em 30 de abril de 2012.

Aceito para publicação em 24 de janeiro de 2013.

${ }^{2}$ Laboratório de Anatomia Humana e Comparativa, Curso de Ciências Biológicas, Universidade Federal de Goiás, Campus Jataí, BR364 Km192, Setor Parque Industrial, Jataí, G0 75800-000, Brasil. *Autor para correspondência: taismalysz@yahoo.com.br

${ }^{3}$ Laboratório de Pesquisa em Animais Silvestres (Lapas), Faculdade de Medicina Veterinária da Universidade Federal de Uberlândia (UFU), Av. Amazonas 2245, Jardim Umuarama, Uberlândia, MG 38405-302, Brasil.
}

post mortem por atropelamento em rodovia, foram utilizados para o estudo, obedecendo aos critérios da Lei Vigente (Lei 1.153/95). Através da dissecação, a pele foi completamente removida e os animais foram fixados em solução aquosa de formaldeído a $10 \%$. Através de um acesso dorso-lateral, os músculos glúteo superficial, bíceps femoral e glúteo médio foram seccionados no seu local de inserção e rebatidos. Desta forma foi possível visualizar a origem e a distribuição do nervo isquiático, em ambos os antímeros dos animais. As imagens foram registradas com câmera fotográfica digital (Câmera Sony a200, 10.2mpx) e os resultados foram descritos com base na Nomina Anatômica Veterinária. Os dados 
da origem do nervo isquiático nos dois espécimes estudados mostraram que esta ocorre a partir dos ramos ventrais de L6 e S1, podendo ter contribuição de S2. Após a sua emergência pelo forame isquiático maior, em ambos os antímeros, o nervo isquiático fornece ramos para suprir os músculos glúteo médio, glúteo profundo, glúteo superficial, gluteobíceps, bíceps da coxa, semimembranoso, semitendinoso e gastrocnêmio. Próximo ao meio da coxa o nervo isquiático divide-se em nervo tibial e nervo fibular comum os quais inervam os músculos da região distal do membro pélvico. Além disso, o nervo cutâneo caudal da sura pode se originar dos nervos fibular comum ou do nervo tibial. Em conclusão, nos espécimes de Mazama gouazoubira estudados, o nervo isquiático teve sua origem a partir dos ramos ventrais espinais de L6 e S1, podendo ou não ter a contribuição de S2. Na sua distribuição originam-se o nervo glúteo caudal, o nervo cutâneo femoral caudal e ramos musculares, que, conjuntamente inervam os músculos glúteo médio, glúteo profundo, glúteo superficial, gluteobíceps, bíceps da coxa, semitendinoso, semimembranoso, adutor e gastrocnêmio. Distalmente o nervo isquiático bifurca-se em nervo tibial e fibular comum, os quais inervam a porção distal do membro pélvico.

TERMOS DE INDEXAÇÃO: Nervo isquiático, morfologia, Mazama gouazoubira.

\section{INTRODUÇÃO}

Conhecido como veado-catingueiro, Mazama gouazoubira (Fischer, 1814), um mamífero de pequeno porte, é uma das oito espécies de ruminantes da família Cervidae que vivem no Brasil. Este cervídeo é abundante e amplamente distribuído pela América Central e América do Sul, podendo apresentar-se em florestas, matas ciliares de galeria, até cerrados abertos, campos e capoeiras (Duarte 1997). Trata-se de uma espécie que apresenta chifres não ramificados e pelagem geralmente na coloração marrom acinzentada com regiões ventrais brancas na cauda (Tiepolo \& Tomas 2006, Ferreira et al. 2011).
Em ruminantes, o nervo isquiático, considerado o maior nervo do corpo, apresenta-se com fibras nervosas sensitivas e motoras que derivam geralmente do último nervo lombar e do primeiro e segundo componentes sacrais do plexo lombossacral e que inervam o membro pélvico do animal (Godinho et al. 1987, Getty 2008, Dyce et al. 2010). 0 estudo anatômico do nervo isquiático é importante por ser suscetível a lesões compressivas, estiramentos, laceração ou transecção completa. Estas lesões podem ser decorrentes de traumas que incluem fraturas e seus reparos, luxações e administração de injeções (Oliver et al. 1997). A lesão do nervo isquiático pode levar a analgesia e anestesia da porção distal do membro pélvico, exceto a pele da parte medial do membro que é suprida pelo nervo safeno, ramo do nervo femoral (Smith 1993, Dyce et al. 2010).

Assim, considerando a necessidade de contribuir para o estudo morfológico da espécie e fornecer embasamento teórico para abordagens clínicas e cirúrgicas, este estudo teve como objetivo descrever a origem e a distribuição do nervo isquiático no veado-catingueiro.

\section{MATERIAL E MÉTODOS}

Dois animais da espécie Mazama gouazoubira, obtidos post mortem por atropelamento em rodovia, foram utilizados para o estudo da origem e distribuição do nervo isquiático, obedecendo aos critérios da Lei Vigente (Lei 1.153/95). Através da dissecação, a pele foi completamente removida e posteriormente os animais foram fixados em solução aquosa de formaldeído a 10\%, com injeções intramusculares e intracavitárias e sequencialmente, imersos nesta mesma solução.

Através de um acesso dorso-lateral, os músculos glúteo superficial, bíceps femoral e glúteo médio foram seccionados no seu local de inserção e rebatidos. Desta forma foi possível visualizar a origem e a distribuição do nervo isquiático, em ambos os antímeros dos animais. As imagens foram registradas com câmera fotográfica digital (Câmera Sony a200, 10.2mpx) e os resultados foram descritos com base na Nomina Anatômica Veterinária (International Committee on Veterinary Gross Anatomical Nomenclature 2005).

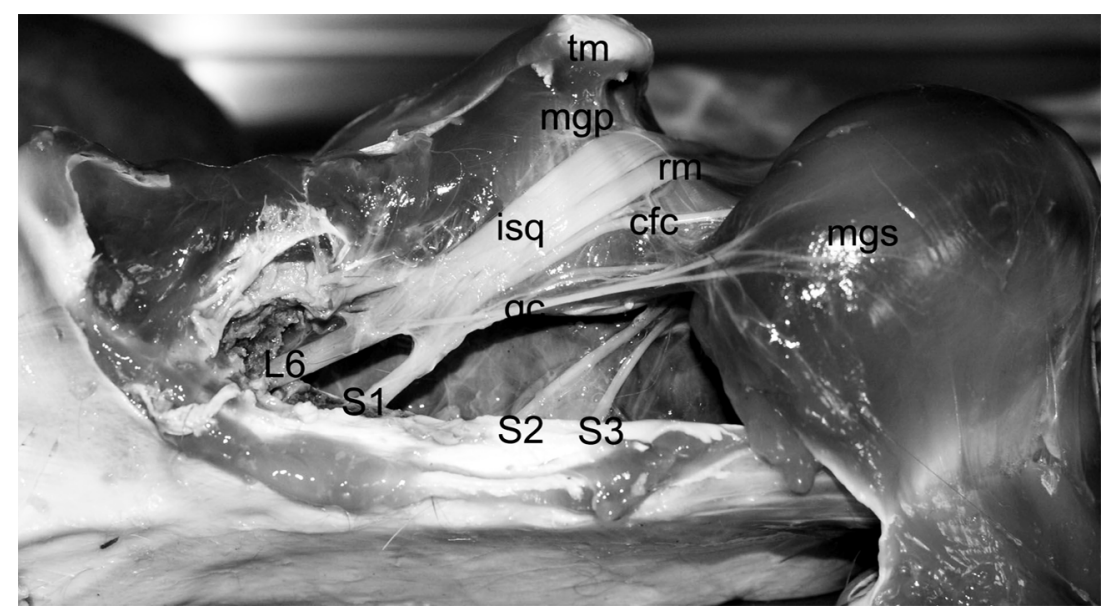

Fig.1. Vista dorsal da origem do nervo isquiático do veado-catingueiro a partir dos ramos ventrais espinais de L6 e S1. Observam-se os nervos glúteo caudal (gc) e o cutâneo femoral caudal (cfc) oriundos do nervo isquiático (isq). Sequencialmente, o nervo isquiático, ao nível do trocanter maior do fêmur (tm), emite também ramos musculares ( $\mathrm{rm}$ ); mgs: músculo glúteo superficial; mgf: músculo glúteo profundo. 


\section{RESULTADOS}

Em ambos os espécimes de Mazama gouazoubira, o nervo isquiático teve as suas origens a partir dos ramos ventrais do sexto nervo lombar (L6) e do primeiro nervo espinal sacral (S1; Fig.1). Em um dos animais também houve contribuição do ramo ventral do segundo nervo espinal sacral (S2) (Fig.2).

Após sua emergência pelo forame isquiático maior, próximo ao trocanter maior do fêmur, originaram-se os nervos glúteo caudal e cutâneo femoral caudal (Fig.1-3). 0 primeiro seguiu para a região glútea do membro, para suprir os músculos glúteo médio e o gluteobíceps, e o segundo para toda a extensão da coxa inervando os músculos glúteo profundo, glúteo superficial e bíceps femoral e a pele da região caudal do membro pélvico. Sequencialmente, a partir da sua borda caudal, o nervo isquiático enviou diversos ramos musculares para a região póstero-lateral do membro inervando os músculos adutor, o semimembranoso, bíceps femoral e o gastrocnêmio. Estes ramos tiveram sua origem aparentemente agrupada, as quais sequencialmente atingiram os músculos-alvo (Fig.1-3).

Próximo ao meio da coxa, na região dos músculos semimembranoso e adutor da coxa, o nervo isquiático dividiu-se em nervo fibular comum e nervo tibial, os quais seguiram para inervar a porção distal do membro pélvico. Imediatamente após a bifurcação do nervo isquiático em fibular comum e em tibial, nos dois antímeros do animal I, o nervo tibial originou o nervo cutâneo caudal da sura, o qual acompanhou a fáscia crural suprindo pele da região póstero-lateral da perna (Fig.2). Entretanto o antímero direito do animal II, este nervo se originou a partir do nervo fibular (Fig.1 e 3), e, no antímero esquerdo deste animal o nervo esteve ausente.

Após a bifurcação, o nervo tibial seguiu entre as duas porções do m. gastrocnêmio inervando o mesmo e fornecendo ramos musculares para os músculos poplíteo, sóleo e flexor digital profundo e flexor digital superficial. Próxi-
A

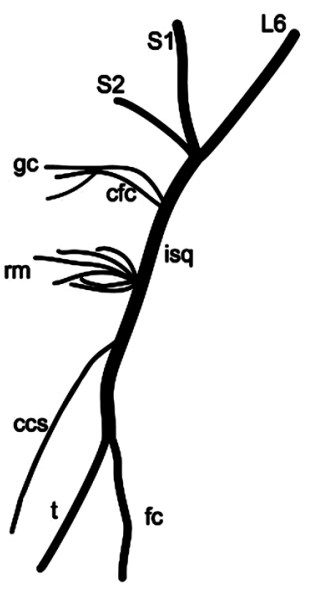

B

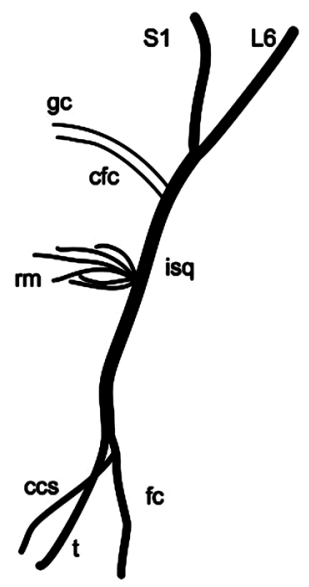

Fig;2. Os esquemas representam a origem e distribuição do nervo isquiático no veado-catingueiro (animal I em A e animal II em B). L6, S1 e S2: ramos nervosos ventrais que originaram o nervo isquiático (isq); gc $=$ Nervo glúteo caudal; $\mathrm{cfc}=$ Nervo cutâneo femoral caudal; $\mathrm{rm}=$ Ramos musculares; $\mathrm{ccs}=$ Nervo cutâneo caudal da sura; fc = Nervo fibular comum; $t=$ Nervo tibial.

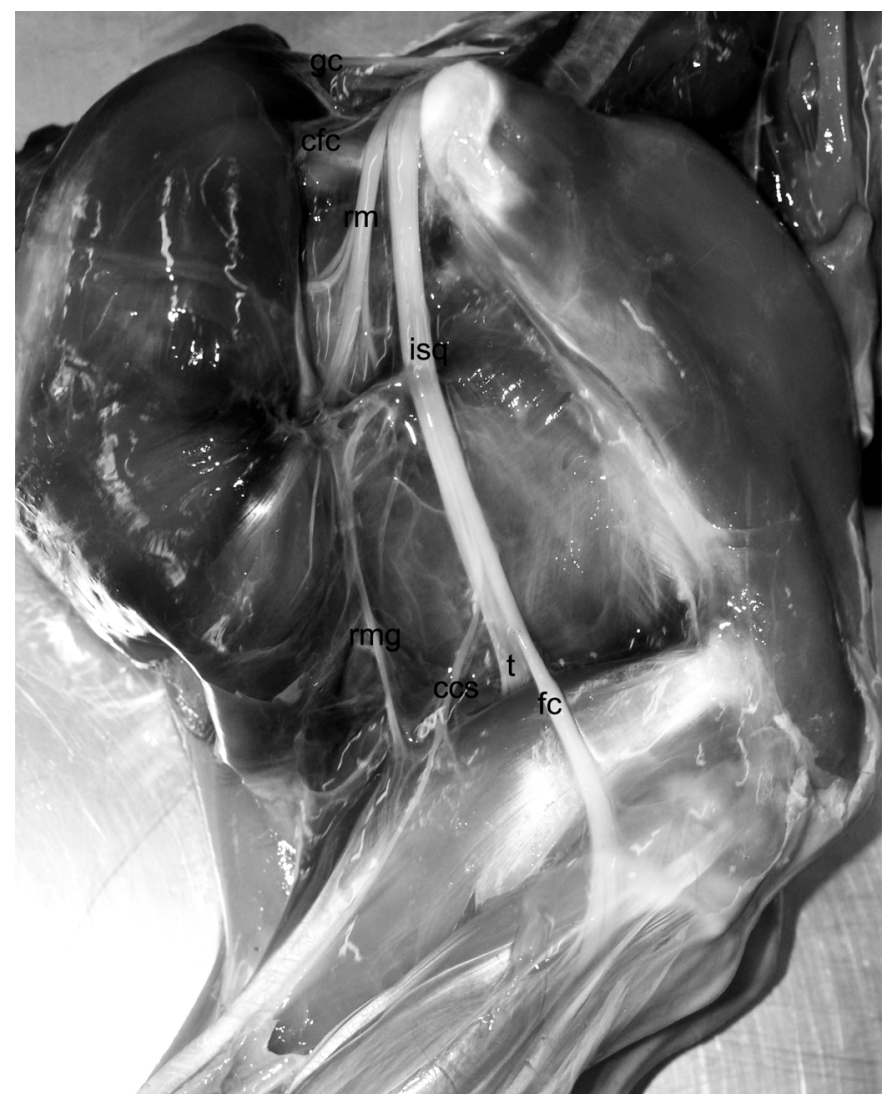

Fig.3. Vista lateral do membro pélvico do veado-catingueiro em que o nervo isquiático (isq) emite os nervos glúteo caudal (gc) e cutâneo femoral caudal (cfc), sequencialmente emite ramos musculares (rm) que suprem os músculos adutor, semimembranoso, bíceps femoral e o gastrocnêmio (rmg). 0 nervo isquiático (isq) bifurca-se em nervo tibial (t) e nervo fibular comum (fc), do qual se originou o nervo cutâneo caudal da sura (ccs).

mo a tuberosidade calcânea o n. tibial dividiu-se em nervo plantar lateral e medial, os quais seguiram, respectivamente, para a região planto-lateral e médio-plantar do tarso.

0 nervo fibular comum percorreu a região craniolateral da perna, passou entre os músculos fibular longo e extensor lateral dos dedos e dividiu-se em nervo fibular superficial e profundo. 0 primeiro inerva o m. extensor lateral dos dedos e o segundo supre os músculos fibular longo, extensor digital longo, tibial cranial e fibular terceiro. Distalmente ambos seguiram para o dorso da pata.

\section{DISCUSSÃO}

A coluna vertebral de Mazama gouazoubira apresenta sete vértebras cervicais, treze vértebras torácicas, seis vértebras lombares e cinco vértebras sacrais. Trinta e dois pares de nervos espinais partem da medula espinal, sendo oito cervicais, treze torácicos, seis lombares e cinco sacrais. A medula dos animais desta espécie apresenta duas intumescências e termina ao nível da terceira e quarta vértebras sacrais (Lima et al. 2010).

Os dados da origem do nervo isquiático nos dois espécimes estudados mostraram que esta ocorre a partir dos ramos ventrais de L6 e S1, podendo ter contribuição de 
S2. Estes resultados corroboram com os descritos por De Camargo et al. (2008) onde o nervo isquiático apresenta origem a partir dos ramos ventrais de L6, S1, S2 e S3, com menor contribuição destes dois últimos.

De uma forma geral, os dados que se referem à origem do nervo isquiático em ruminantes da família Bovidae e são semelhantes aos encontrados em M. gouazoubira (família Cervidae) e também evidenciam a presença de variação anatômica, conforme descrição apresentada no Quadro 1. Pesquisas mostram que geralmente o nervo isquiático de caprinos da raça Saanem (Lima et al. 2008, Nascimento et al. 2011) e bovinos azebuados (Campos et al. 2003, Ferraz et al. 2006) apresentam simetria bilateral e origem a partir dos ramos ventrais de L6, S1 e S2. Em ovinos da raça Morada Nova, no entanto, por existir variação no número de vértebras lombares, os autores descrevem que a origem do nervo isquiático na maioria dos animais ocorre a partir dos ramos ventrais de L7, S1 e S2 (Sousa 2008).

Embora a família Bovidae seja filogeneticamente a mais próxima da Cervidae, e possivelmente por isso a origem do nervo isquiático seja mais semelhante, podemos também fazer comparações com outras famílias de animais. Através desta foi possível evidenciar a presença de variações anatômicas relativas à origem do nervo isquiático assim como uma possível tendência evolutiva ao aumento no número de ramos ventrais advindas de segmentos medulares lombares que contribuem para a origem do nervo isquiático.

Na família Suidae, em porcos sem raça definida e javalis (Sus scrofa scrofa), a maioria dos animais apresentou origem do nervo isquiático respectivamente a partir dos ramos ventrais de L6, L7 e S1 (Mihelic et al. 2004) e L5, L6 e
S1 (Iglesias et al. 2011). No que se refere à família Caviidae, no preá silvestre do semiárido (Galeaspixii) e no mocó (Kerodonrupestris), geralmente o nervo isquiático origina-se, respectivamente, a partir dos ramos ventrais de L6, L7 e S1 e L6 (Oliveira et al. 2010) L6 ou L7, S1 e S2 (Santos et al. 2006). Entre carnívoros, o mais comum é o nervo isquiático originar-se dos ramos ventrais de L6, L7 e S1 no mão-pelada Procyoncancrivorus (Pereira et al. 2011) e a partir de L6, L7, S1 e S2 no gato doméstico (Guimarães et al. 2005) e no cão doméstico (Evans \& De Lahunta 1994, Getty 2008). Em humanos, o nervo isquiático origina-se a partir dos ramos ventrais de L4, L5, S1, S2 a S3 (Gray 1988, Dângelo \& Fattini 2000, Moore \& Daley 2007).

Após a sua emergência pelo forame isquiático maior, em ambos os antímeros, o nervo isquiático em Mazama gouazoubira, fornece ramos para suprir os músculos glúteo médio, glúteo profundo, glúteo superficial, gluteobíceps, bíceps da coxa, semimembranoso, semitendinoso e gastrocnêmio. Próximo ao meio da coxa o nervo isquiático divide-se em nervo tibial e nervo fibular comum os quais inervam os músculos da região distal do membro pélvico. Além disso, como também descrito em Javalis (Iglesias et al. 2011) o nervo cutâneo caudal da sura pode se originar dos nervos fibular comum ou do nervo tibial.

Corroborando com nossos resultados, De Camargo et al. (2008), também no veado-catingueiro, descrevem ramos nervosos em quantidade variável entre os animais e entre os antímeros, os quais suprem os músculos glúteo profundo, glúteobíceps, gêmeos, semitendíneo e semimembranáceo. Segundo o autor, após a emissão destes ramos musculares, o nervo isquiático bifurca-se em tibial e fibular comum.

Quadro 1. Quadro representativo da origem do nervo isquiático em diferentes espécies mamíferos

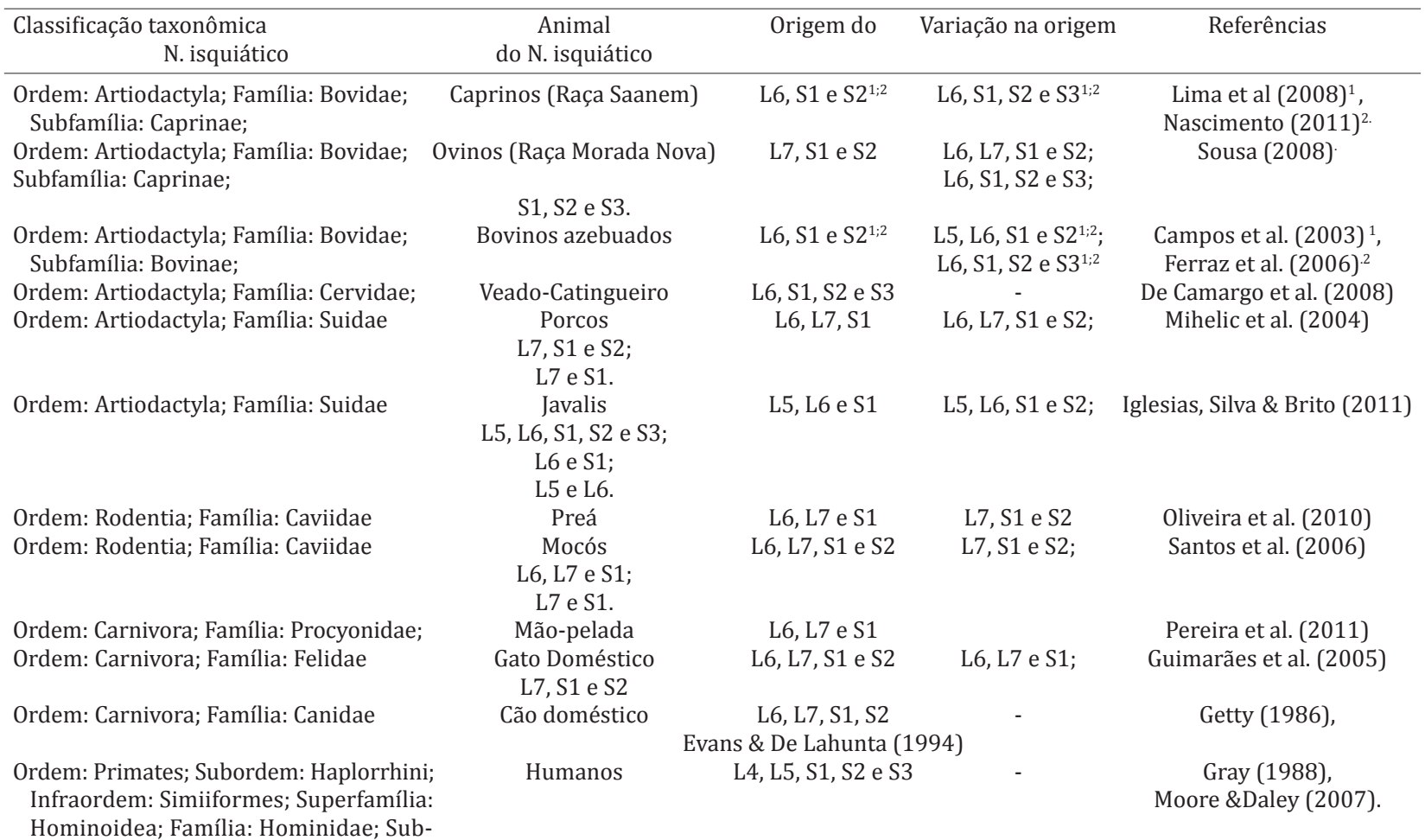

família: Homininae; Genero: Homo 
Pelo descrito, o nervo isquiático inerva os músculos extensores do quadril, os músculos flexores de joelho e os músculos da porção distal do membro. Sobre os ramos musculares, de acordo com Getty (2008), ao nível do trocanter maior do fêmur e distalmente ao mesmo, o nervo isquiático libera diversos ramos, de vários tamanhos e espessuras, que se irradiam de modo semelhante a um leque, inervando o músculo gluteobíceps, o músculo semitendinoso e o músculo semimembranoso. Algumas das fibras, após perfurarem os músculos, inervam a área cutânea na superfície caudal da coxa. Estes ramos sensitivos são designados como os nervos caudais das nádegas, no ovino e no caprino.Em nosso estudo descrevemos a presença de um ramo muscular partindo da borda caudal do nervo isquiático (possivelmente pela porção tibial do nervo) que supre o músculo gastrocnêmio. Este ramo não foi previamente descrito por outros autores.

De forma semelhante à descrita neste estudo, em caprinos da raça Saanen (Lima et al. 2008, Nascimento et al. 2011) e em bovinos azebuados (Campos et al. 2003) os autores descrevem que os nervos isquiáticos fornecem ramos musculares para os músculos glúteo médio, glúteo profundo, gluteobíceps, semitendinoso e semimembranoso, em ambos os antímeros, antes de dividir-se em nervo tibial e fibular comum. No estudo de Sousa (2008), em ovinos, os autores descreveram a inervação dos músculos gluteobíceps, semitendinoso, semimembranoso e, em 25\% dos animais, identificaram também ramo muscular suprindo o músculo quadríceps da coxa.

De forma semelhante aos resultados descritos em nosso estudo, em Javalis (Sus scrofa scrofa), o nervo emitiu ramos para os músculos glúteos médio e superficial, bíceps femoral, semimembranáceo, semitendíneo, piriforme, adutor e tensor da fáscia lata (Iglesias et al. 2011).

Estudos em mocós mostraram que o nervo isquiático supre os músculos glúteo médio, glúteo profundo e glúteo superficial (Santos et al. 2006). Entretanto, em preás não foram observados ramos inervando os músculos glúteo médio e glúteo superficial, somente inervando o músculo glúteo profundo (Oliveira et al. 2010). Esta inervação do glúteo profundo, juntamente com inervação dos músculos gêmeos, quadrado femoral e piriforme é também descrita para gatos (Guimarães et al. 2005), cães (Schwarze \& Schröder 1970) e para carnívoros (Dyce et al. 2010). De acordo com Pereira et al. (2011) o nervo isquiático do mão-pelada supre os músculos glúteo bíceps, glúteo médio, glúteo profundo, quadrado femoral, gêmeos, adutor magno, bíceps femoral, semitendíneo e semimembranoso.

De acordo com Swindler \& Wood (1973), chimpanzés, balbuínos e humanos possuem a mesma distribuição, inervação e ramificação. Nestes também não ocorre a inervação da musculatura glútea pelo nervo isquiático, mas existe inervação do músculo adutor magno por este nervo. Em Cebus libidinosus, da mesma forma, não foram descritos ramos suprindo musculatura glútea e o músculo adutor magno não se apresenta suprido pelo nervo isquiático e sim pelo nervo obturatório (Aversi-Ferreira et al. 2011).

Em conclusão, nos espécimes de Mazama gouazoubira estudados, o nervo isquiático teve sua origem a partir dos ramos ventrais espinais de L6 e S1, podendo ou não ter a contribuição de S2. Na sua distribuição originam-se o nervo glúteo caudal, o nervo cutâneo femoral caudal e ramos musculares, que, conjuntamente inervam os músculos glúteo médio, glúteo profundo, glúteo superficial, gluteobíceps, bíceps da coxa, semitendinoso, semimembranoso, adutor e gastrocnêmio. Distalmente o nervo isquiático bifurca-se em nervo tibial e fibular comum, os quais inervam a porção distal do membro pélvico. A partir do nervo tibial ou do nervo fibular comum origina-se o nervo cutâneo caudal da sura, o qual supre a pele da região lateral da perna.

Salientamos que o conhecimento da origem, distribuição e musculatura inervada pelo nervo isquiático no veado-catingueiro pode contribuir para a clínica de ruminantes, facilitando desde o exame físico e funcional até a terapêutica que inclui a injeção de fármacos intramusculares, bloqueios anestésicos e abordagens cirúrgicas.

\section{REFERÊNCIAS}

Aversi-Ferreira R.A.G.M.F., Marin K.A., Silva F.O.C. \& Aversi-Ferreira T.A. 2011. Comparative anatomy of the thigh nerves of Cebus libidinosus (Rylands et al., 2000). Pesq. Vet. Bras. 31:261-266.

Campos D.B., Silva F.O.C., Severino R.S., Drummond S.S., Lima E.M.M., Bombonato P.P. \& Santana M.I.S. 2003. Origem e distribuição dos nervos isquiáticos em fetos de bovinos azebuados. Ars Vet. 19:219-223.

Dângelo J.G. \& Fattini C.A. 2000. Anatomia humana sistêmica e segmentar: para o estudante de medicina. $2^{\underline{a}}$ ed. Editora Atheneu, São Paulo, p.243246.

De Camargo V.M.F., Guerra R.R., Tranquilim M.V. \& Campos D.B. 2008. Origem e distribuição dos nervos isquiáticos no veado-catingueiro (Mazama gouazoubira). Anais 35을 Conbravet, Gramado, RS. 3p. (Resumo)

Duarte J.M.B. 1997. Biologia e Conservação de Cervídeos Sul-Americanos: Blastocerus, Ozotoceros e Mazama. Funep, Jaboticabal. 238p.

Dyce K.M., Sack W.O. \& Wensing C.J.G. 2010. Tratado de Anatomia Veterinária. $4^{\mathrm{a}}$ ed. Editora Guanabara Koogan, Rio de Janeiro. 834p.

Evans H.E. \& De Lahunta A. 1994. Guia para Dissecção do Cão. Guanabara, Rio de Janeiro. 206p.

Ferraz R.H.S., Lopes G.R., Melo A.P.F. \& Prada I.L.S. 2006. Estudo anatômico da porção intrapélvica do nervo isquiático em fetos de bovinos azebuados. Braz. J. Vet. Res. Anim. Sci. 43:302-308.

Ferreira A.O., Morini A.C., Favaron P.O., Passos C.C., Campos D.B., Miglino M.A. \& Guerra R.R. 2011. Avaliação morfológica das membranas fetais e da placenta de Mazama gouazoubira (veado-catingueiro) de vida livre no terço inicial da gestação. Pesq. Vet. Bras. 31:631-635.

Getty R. 2008. Sisson/Grossman, Anatomia dos Animais domésticos. Vol.1. 5aㅡ ed. Editora Guanabara Koogan, Rio de Janeiro, p.1063-1077.

Godinho H.P., Cardoso F.M. \& Nascimento J.F. 1987. Anatomia dos Ruminantes Domésticos. Universidade Federal de Minas Gerais, Belo Horizonte. $438 \mathrm{p}$.

Gray H. 1979. Gray's Anatomy. Editora Guanabara Koogan, Rio de Janeiro. $1147 \mathrm{p}$.

Guimarães G.C., Machado M.R.F., Santos A.L.Q., Vieira L.G., Souza A.G., Silva J.M.M. \& Kaminishi A.P.S. 2005. Origem e distribuição do nervo isquiático no gato doméstico (Felis catus domesticus Linnaeus, 1758). Biosci. J. 21:189-195.

Iglesias L.P., Silva F.O.C. \& Brito T.R. 2011. Origem e distribuição do nervo isquiático de Javalis (Sus scrofa scrofa). Revta Biotemas 24:141-145.

International Committee on Veterinary Gross Anatomical Nomenclature 2005. Nomina Anatomica Veterinaria. $5^{\text {th }}$ ed. Editorial Committee, Hannover. $166 \mathrm{p}$

Lima E.M.M., Silva F.O.C., Severino R.S., Drummond S.S., Campos D.B., Santana M.I.S. \& Moraes D.D.A. 2008. Origem e distribuição dos nervos isquiáticos em caprinos da raça Saanen. Ciência Rural 38:372-377. 
Lima F.C., Santos A.L.Q., Lima B.C., Vieira L.G. \& Hirano L.Q.L. 2010. Topographic anatomy of the spinal cord: Vertebromedullary relationships in Mazama gouazoubira Fisher, 1814 (Artiodactyla: Cervidae). Acta Sci. Biol. Sci. 32:189-194.

Mihelic D., Gjurcevic-Kantura S., Markovinovic A., Damjanovic T. \& Trbojevic-Vukicevic T. 2004. Variations of formation of n. femoralis, n. obturatorius and n. ischiadicus in pigs. Veterinarski Arhiv, Zagreb, 74:261-270.

Moore K. \& Daley A. 2007. Anatomia Orientada para a Clínica. 5ª ed. Editora Guanabara Koogan, Rio de Janeiro, p.308-309.

Nascimento R.M., Scheree P.O., Palhano H.B., Barbosa C.G. \& Abidu-Figueiredo M. 2011. Origem e distribuição antimérica dos nervos isquiáticos em caprinos recém-natos da raça Saanen. Revta Bras. Med. Vet. 33:177183.

Oliveira G.B., Rodrigues M.N., Sousa E.S., Alburquerque J.F.G., Moura C.E.B., Ambrosio C.E., Miglino M.A. \& Oliveira M.F. 2010. Origem e distribuição dos nervos isquiáticos do preá. Ciênc. Rural 40:1741-1745.

Oliver J.E., Lorenz M.D. \& Kornegay J.N. 1997. Handbook of Veterinary Neurology. $3^{\text {rd }}$ ed. W.B. Saunders, Philadelphia, p.115-117.

Pereira K.F., Paranaiba J.F.F.S., Helrigle C. \& Araújo E.G. 2011. Origem e dis- tribuição anatômica do nervo isquiático de Mão-Pelada. Pesq. Vet. Bras. 31(Supl.1):74-78.

Santos R.C., Alburquerque J.F.G., Silva M.C.V., Moura C.E.B., Chagas R.S.N., Barbosa R.R. \& Miglino M.A. 2006. Anatomia do nervo isquiático em mocós (Kerodon rupestris Wied, 1820) aplicada à clínica de animais silvestres. Braz. J. Vet. Res. Anim. Sci. 43:647-653.

Schwarze E. \& Schröder L. 1970. Compendio de Anatomia Veterinária: sistema visceral. Acribia, Zaragoza, p.82-90.

Smith B.P. 1993. Tratado de Medicina Interna de Grandes Animais. Vol.2. Editora Manole, São Paulo. 900p.

Sousa E.S. 2008. Anatomia do nervo isquiático em ovinos da raça Morada nova aplicada à clinica de pequenos ruminantes. Dissertação de Mestrado em Ciência Animal, Universidade Federal Rural do Semi-Árido, Mossoró, RN. 41p.

Swindler D.R. \& Wood C.D. 1973. An Atlas of Primate Gross Anatomy. University of Washington Press, Washington, DC. 370p.

Tiepolo L.M. \& Tomas W.M. 2006. Ordem Artiodactyla, p.283-300. In: Reis N.R., Peracchi A.L., Pedro W.A. \& Lima I.P. (Eds), Mamíferos do Brasil. Vol.1. Universidade Estadual de Londrina, Londrina. 